\title{
Sympathy of Movement: Expanding Coaching Abilities through Phenomenological Discussion
}

\author{
Naoki Matsuyama and Jun Tsuchiya \\ Graduate School of Sport Sciences, Waseda University, 2-579-15 Mikajima, Tokorozawa, Saitama 359-1192 Japan \\ E-mail: m112217n@gmail.com \\ [Received April 12, 2016; Accepted January 5, 2017; Published online January 25, 2017]
}

\begin{abstract}
This study clarifies abilities that enable "sympathy of movement" (Mitvollziehen der Bewegung). Moreover, it discusses the methodological directionality to expand these abilities from coaches' and researchers' standpoints, using five discussions by highlighting Husserl's Phenomenology. "Sympathy of movement" refers to sympathizing with an athlete's performance and interpreting their experience from a coaching perspective. Previously, Kaneko indicated that "sympathy of movement"' is performed using three coaching activities: the observation of movement, "inquiry," and "virtual self-movement." Using these activities, coaches can consider and provide appropriate advice for each individual. Previous studies have highlighted the importance of expanding these abilities; however, the manner in which these abilities should be expanded has yet to be clarified. Thus, this study employs three activities to clarify a methodological directionality to expand these abilities from a phenomenological perspective. In addition, it uses five discussions to indicate the necessity for coaches to learn the difference between external and internal standpoints on performance. Furthermore, researchers should focus on the phenomenological perspective.
\end{abstract}

Keywords: experience during performance, body intelligence, observation of movement, association with knowledge, perception principle

\section{Introduction}

This study clarifies abilities that enable "sympathy of movement" (Mitvollziehen der Bewegung) (Meinel, 1960/1981, p. 127). Moreover, it uses five discussions by highlighting Husserl's Phenomenology to discuss a methodological directionality to expand these abilities from coaches' and researchers' standpoints.

"Sympathy of movement" refers to sympathizing with an athlete's performance from a coaching perspective. This ability corresponds to a "precondition to coach another person" (Meinel, 1960/ 1981, p. 453). This is because a coach can consider and provide appropriate advice for each individual by accurately interpreting an athlete's performance and experience. Therefore, some previous studies have indicated the importance of expanding coaching abilities through practice at training institutions for coaches and physical education teachers.1),2) The methodological directionality should be discussed by interpreting the phenomenon and abilities of "sympathy of movement." However, these have yet to be clarified.

From the phenomenological perspective, the concept of sympathy is to project consciousness into an observed other and interpret other experiences (Fremderfahrung) through an observer's subjective belief (Smith, 1989, pp. 112, 115). Applying this interpretation to coaches and athletes, the aim is to project the coach's consciousness into an observed performance and interpret the athlete's experience, such as consciousness and sense of performance, in the coach's subjective belief. Therefore, this study focuses on how coaches can project their consciousness into an observed performance and interpret the athlete's experience, highlighting Husserl's phenomenology.

To date, "sympathy of movement" has been captured using three coaching activities: the observation of movement, "inquiry"3) (Kaneko, 2005, p. 199), and "virtual self-movement"4),5) (virtuelle Selbstbewegung) (Kaneko 1987, p. 123). Meinel (1960/1981, p. 176) indicated that observation of movement focuses not on the objective observation of a performance from an external viewpoint but on 
subjective "simultaneous experience of movement" in an athlete's performance. ${ }^{6}$ However, even if a coach projects her or his consciousness into an athlete's performance and tries to interpret athlete's experience through the observation of movement, the coach can only gain a rough or partial impression of it (Kaneko, 1987, p. 123). To comprehensively interpret athletes' experiences, the coach should interpret not only their performance as an observed subject (Gegen-stand) from an external standpoint but also imagine this performance from an independent standpoint using "inquiring" and "virtual selfmovement" from an internal standpoint. Therefore, this study focuses on "sympathy of movement" using three activities and discusses the methodological directionality to expand these abilities by highlighting Husserl's phenomenology. Furthermore, this study indicates that coaches should learn the difference between external and internal standpoints on performance.

Furthermore, this study focuses on research methods of previous studies tried to interpret athlete's experience as internal viewpoint using interview or descriptive survey based on Husserl's phenomenology. To date, researches tried employing descriptive and interview survey methods based on Husserl's phenomenology using sequential photos of performances and enquired into athletes' experience in each designated phase. However, from a phenomenological perspective, this method has a few limitations.

For example, in phenomenology, a performance is interpreted as a gestalt, and it is imagined from an athlete's consciousness, which overlaps past, present, and future processes of performance ${ }^{7}$. It means phases that are cropped from the athlete's consciousness of performance have been described as different from those seen from the objective viewpoint, implying that the border of one phase overlaps with the other in this performance (Muraki, 1993, p. 975). Therefore, researchers should discuss a concrete methodology to retain the overlapping structure of performance in the athlete's experience and should interpret the experience using this structure.

\section{Method and Discussion Processes}

The central concern in phenomenology is to return to embodied, experiential meanings regard- ing experiences in a phenomenon (Finlay, 2009, p. 6). Similarly, Wertz (2005, p. 175) stated that "phenomenology is low-hovering, in welling, meditative philosophy that glories in concreteness of person-world relations and accords lived experience, with all its indeterminacy and ambiguity, primacy over the known." Since this study focuses on coaches' experience in 'sympathy of movement" and tries to interpret this phenomenon, phenomenological discussion is one approach to achieve the aim of this study.

To date, previous studies have also discussed athlete's performance or consciousness using phenomenology. For example, Meinel (1960/1981, p. 141) discussed qualities of elasticity, flowability, and rhythm in performance and suggested the importance to interpret a performance as a gestalt. Similarly, Kaneko (2005) discussed athletes' consciousness and systematically clarified methodology to inspire athletes' consciousness. However, no study has focused on coaches' experience in "sympathy of movement" and a methodological directionality to expand abilities of "sympathy of movement." Therefore, this study describes ways to clarify the concept of "sympathy of movement," highlighting Husserl's phenomenology in five discussions.

The first discussion uses the schema of natural science to discuss the possibility of directly understanding an athlete's performance experience. Further, this study negates this possibility from the phenomenological perspective. The second discussion uses the schema of phenomenology to discuss the possibility of interpreting an athlete's experience. This study affirms this possibility and further interprets "sympathy of movement" as being an intuitive belief acquired through empirical knowledge.

Based on these discussions, the third discussion identifies a key concept that enables "sympathy of movement." Here, an intuitive belief is further discussed as an intuition using empirical knowledge to associate an observed movement with the coach's past performance experience. This concept is called "association" in Husserl's phenomenology. Based on this key concept, the fourth discussion examines how coaches enable "sympathy of movement" using three coaching activities. The final discussion explores a methodological directionality to expand coaching abilities from coaches' and researchers' standpoints. 


\section{First Discussion of the Phenomenon Using the Schema of Natural Science}

First, this study focuses on the schema of natural science regarding subjectivity and objectivity. Furthermore, it discusses whether coaches can directly understand athletes' experiences. This is found to be impossible because it requires that athletes' experiences must be directly understood as consciousness and sensations during a performance. ${ }^{8)}$ Thus, the concept of subjectivity and objectivity is used to interpret the coach as the observer and an athlete's experience as an observed subject. Subjectivity denotes the coach's viewpoint, whereas objectivity refers to athletes' experiences. Furthermore, objectivity is interpreted as the absolute meaning of a subject (i.e., athletes' objective experiences mean that they have an absolute consciousness and sense during their performance, which a coach cannot understand).

However, athletes' consciousness is created by an image of the generation of performance. Thus, coaches are unable to objectively understand this image in athletes' experience itself. In addition, since subjectivity varies with each coach, an athlete's experience may be interpreted by differing subjectivities of coaches. Hence, coaches cannot understand athletes' experiences unless they imagine and interpret them by observing successive physical expressions, such as facial expressions, physical gestures, and words. ${ }^{9)}$ Therefore, this study indicates that subjectivity and objectivity in the schema of natural science is not satisfactory as the fundamental principle to interpret the phenomenon. Therefore, coaches cannot directly understand athletes' experiences from a coaching standpoint.

\section{Second Discussion Using the Phenomeno- logical Schema}

Second, this study furthers the discussion using the schema of Husserl's phenomenology. Phenomenological discussion begins with Descartes's skepticism and interprets a cognitive phenomenon using subjective belief.

Generally, we try to interpret a cognitive phenomenon using the schema of natural science. We tend to believe the existence of meaning as being subjectivity in the world. However, in Husserl's phenomenology, since we can infinitely distrust the existence of the world using Descartes's skepticism, the essentiality of the cognitive phenomenon should be interpreted by subjective belief, which is based on "Cogito." 10) Therefore, Husserl's phenomenology does not postulate the existence of the world $^{11)}$ and further interprets the essentiality of a cognitive phenomenon through a reduced framework of subjective belief.

In this context, in the phenomenological schema, a subject, such as an athlete's experience, is interpreted as "transcendence" (Husserl, 1950/2001, p. 58), which means that we cannot understand its existence in the world. Similarly, the cognitive phenomenon is interpreted as "transcendental subjectivity," (Husserl, 1973/2012, p. 409), which is a subjective belief and merely interprets the athlete's experience as "transcendence." 12)

Based on this schema, this study indicates that coaches can interpret athletes' experiences during a performance. This is because, when coaches try to interpret "transcendence," they observe that something exists despite the quality of interpretation.

\section{Third Discussion Regarding a Key Concept to Interpret the Phenomenon}

According to the phenomenological schema, a coach can infinitely doubt an athlete's experience as having existence in the world. However, in "transcendental subjectivity," the coach cannot doubt a subjective belief itself would go against the athlete's experience.

Generally, when we interpret another's experience from their physical expression, this belief is given as an intuition. For example, if we see a crying face, we intuitively and instantaneously interpret a sad feeling as the meaning of this expression. However, in this situation, although we try to project our consciousness into the crying face, which we are observing, from our standpoint, it does not mean that we are sympathizing with the person's experience of crying. This is because it focuses not on the person's experience during crying, but on the meaning of the facial expression as gestalt. Therefore, we might misinterpret her or his experience from the face. She or he might be crying out of happiness. In such a situation, we can closely interpret his or her experience through interviews or questions based on the experience of crying. We can sympathize with the person's ex- 
perience through the crying experience to achieve a goal. Therefore, we should not only focus on physical expression as a gestalt but also experience physical expression as a background. This is because other experiences are intuitively believed through materials (hylē) against phenomenon. Similarly in a coaching situation, "sympathy of movement" is not established only by observation of movement, and coaches should try to collect materials using "inquiry" and "virtual self-movement." Based on these materials, "sympathy of movement" is established. Therefore, the key concept is discussed as the momentum to establish this intuitive belief.

Husserl (1950/2001, p. 87) indicated that belief as an overt intuition accompanies the horizon to enable the intuition. Furthermore, this horizon is interpreted from the relevance of an overt intuition and an organized "passive synthesis" (Husserl, 1950/ 2001, p. 145), which passively integrates materials into an empirical meaning as experience. In terms of incorporating this concept into the phenomenon "sympathy of movement," it means that coaches have an organized "passive synthesis." When they intuitively interpret an athlete's experience using the observation of movement, "inquiry," and "virtual self-movement," they can intuitively associate performance with the empirical meaning through a "passive synthesis" and can interpret the athlete's consciousness through a belief in "transcendental subjectivity." In Husserl's phenomenology, this concept is called "association" (Husserl, 1950/ 2001, p. 46; Husserl, 1952/2001, p. 146).

Therefore, based on the key concept "association," the phenomenon "sympathy of movement" is interpreted in terms of two factors. First, it is interpreted as the belief in "transcendental subjectivity." Second, it is an intuitive belief, which intuitively associates performance with the meaning of an athlete's experience. This study further indicates that since the ability of the phenomenon "sympathy of movement" is shaped by and associated with the organized "passive synthesis," coaches should learn this empirical knowledge. Through this learning, coaches can sophisticate sympathizing with each athlete's experience. It helps to deeply consider an advice and training program to inspire each athlete's consciousness for performance from coaching standpoint. This is because performance is generated by athlete's consciousness.

\section{Fourth Discussion Regarding Abilities Using Three Coaching Activities}

Husserl's keynote regarding others' experience, "sympathy of movement," considers my experience not as other experiences in the approved world but how I interpret another's experience in "transcendental subjectivity" (Hamauzu, 1995). Regarding this keynote, Husserl (1950/2001) used the concept of "association." Using this concept with "transcendental subjectivity," others' experience as "sympathy of movement" is regarded as being intuitively given, using passive references to a "flamed background" or "horizon," which are accumulated through past experiences (Husserl, 1950/ 2001, p. 89). Therefore, this study indicates that abilities that enable "sympathy of movement" as intuition are founded in the relevance of organized "passive synthesis," as background and horizon, and coaching activities as the observation of movement, "inquiry," and "virtual self-movement."

In the case of using the observation of movement, the medium to interpret an athlete's experience is an observed performance. On this occasion, a coach should project their consciousness into the observed performance and interpret an athlete's experience from the quality of the observed performance. Therefore, the ability to use the observation of movement enables the coach to interpret an athlete's experience from an observed performance quality. Furthermore, an athlete's experience is understood through "association," which intuitively associates an observed performance quality with an athlete's experience, using organized "passive synthesis."

In the case of using "virtual self-movement," this is not the action of interpreting an observed performance as an observed object (Gegen-stand) from an external standpoint but the action of imagining the observed performance as her or his own performance from an internal standpoint (Kaneko, 1987, p. 123). Therefore, the medium for interpreting an athlete's experience is the coach's consciousness of the performance, and "sympathy of movement" is performed by reflecting on the coach's image of a performance. Therefore, the ability to use "virtual self-movement" depends on imagining a performance, which is based on the observed performance, using the "organized "passive synthesis," and to deeply sympathize with an athlete's ex- 
perience through reflection on this image.

In the case of "inquiry," the medium of interpreting an athlete's experience is to obtain the athlete's reflection on that experience as consciousness and sensation during performance. Through this activity, a coach can interpret not only overt consciousness but also passive consciousness of performance. Based on these interpretations, the coach can deeply interpret an observed performance using the observation of movement and can imagine a performance using "virtual self-movement." Therefore, contents of "inquiry" are shaped by organized "passive synthesis" toward "sympathy of movement," using the observation of movement and "virtual self-movement." Thus, the ability to use "inquiry" involves reducing the essential experience of performance.

\section{Fifth Discussion Regarding Methodological Directionality to Expand Abilities}

To expand the ability of "sympathy of movement" using the observation of movement in coaching standpoint, this study indicates that coaches should learn the difference between external and internal standpoints on performance. This is because a gap exists between an observed performance from an external standpoint and an athlete's performance from an internal standpoint. For example, in jumping performances in athletics, we tend to interpret the take-off motion, when putting the take-off leg on the ground, from an external standpoint (Schmolinsky, 1978; Killing, 1993; Tidow, 1993). However, jumpers plan their take-off motion before putting the take-off leg on the ground from an internal standpoint (Muraki, 1993, p. 975). If a coach lacks this empirical experience and knowledge, they cannot interpret others' internal experiences.

For "virtual self-movement", this study indicates that coaches should learn the difference between two viewpoints. However, in this case, coaches should learn these differences by focusing on the internal standpoint of their own beliefs. This is because this ability should imagine an observed performance from the coach's internal standpoint. Therefore, to expand this ability, this study mentions that coaches should examine the difference between the external standpoint (using a video camera or mirror) and the internal standpoint (her or his consciousness of a performance).
In the case of "inquiry," this study emphasizes that coaches should learn a questioning technique using phenomenology to reflect on a motion's meaning and value for performance. This is because coaches should focus on both overt consciousness and passive consciousness with regard to performance.

From a research perspective, to interpret athlete experience in internal standpoint, researchers should focus not on asking about their experience using prescript phases and range in performance analysis, rather, they should ask about athlete's experience by a phase in terms of each of their individual viewpoint. This means that researchers should try to set aside judgments against natural attitude in performance analysis. This is because researchers' focus on athlete's experience, his or her consciousness, and sense during performance should be interpreted from a phase in each athlete's individual viewpoint

Based on the above line of thought, phenomenological approach using description or interview is one method to interpret it because this approach has a base to suspend natural attitude and interpret first person's experience in pure consciousness (Finlay, 2009; Martinkova and Parry, 2011). However, "phenomenological research makes our field difficult for novices to access" (Finlay, 2009, p. 7). For example, some researchers seem to try interpreting athlete's experience using prescript phases and range in performance analysis. Based on the above present situation, I show that since Husserl's phenomenology is based on previous studies, which focus on performance phenomenon (Kaneko, 1987; Meinel, 1960/1981), researchers using phenomenological approach should return to the base and interpret phenomenological concept and method thoroughly in order to provide correct information to coaches.

\section{Conclusion}

Using five discussions, this study clarifies the methodological directionality to expand coaching abilities through "sympathy of movement." The first discussion uses schemas of natural science and phenomenology to discuss the interpretation of the phenomenon. The adequacy of this schema is discussed regarding whether coaches can directly understand athletes' consciousness. However, this is 
impossible because an athlete's consciousness is interpreted through an image of performance and coaches cannot directly experience an athlete's performance.

The second discussion interprets the cognitive phenomenon using the schemas of "transcendence" and "transcendental subjectivity" in Husserl's phenomenology. The adequacy of this schema is discussed regarding whether coaches can interpret athletes' experience in a subjective belief. In this case, if coaches misinterpret an athlete's consciousness, there is nevertheless a belief that would go against the athlete's experience. Therefore, the phenomenological schema can be used to interpret the phenomenon "sympathy of movement."

The third discussion uses the phenomenological schema to discuss a key concept to interpret the phenomenon "sympathy of movement." Thus, this study focuses on a horizon of belief in terms of the relevance of overt intuition to an athlete's experience and an organized "passive synthesis." Based on this relevance, this study emphasizes that the phenomenon "sympathy of movement" is interpreted using the concept of "association," which associates a coach's past experience of performance with a belief that would go against the athlete's experience.

The fourth discussion uses the concept "association" to discuss abilities of "sympathy of movement" using three coaching activities: the observation of movement, "inquiring," and "virtual self-movement." On the above discussion, this study indicates that three coaching abilities in the phenomenon "sympathy of movement" is shaped by and associated with the organized "passive synthesis," and the methodological directionality to expand abilities is discussed from this interpretation.

In the final discussion, this study discusses the methodological directionality to expand abilities using three coaching activities. Moreover, it emphasizes the importance of learning the difference between external viewpoint in performance analysis and internal viewpoints in athlete's experience. This is because there are gaps in two viewpoints. Moreover, to compare two viewpoints, phenomenology is one method to interpret athlete's experience. In this case, researchers should focus on athlete's experience and interpret athlete's experience using phenomenological base, which suspends judgments against natural attitude of perfor- mance analysis.

\section{Note}

1) Meinel $(1960 / 1981$, p. 142$)$ indicated that a practice of "sympathy of movement" has the possibility to expand coaching experience, and coaches and physical teachers can acquire certainty and plan their coaching through interpreting athletes' experiences.

2) For coaching experience, Muraki (1993, p. 976) emphasized the importance of focusing on athletes' consciousness during performance. This is because, in practice situations, problems of performance are often founded in an athlete's consciousness of performance, without there being physical conditioning problems.

3) "Inquiry" is the questioning method used to interpret overt and potential consciousness during performance. To do this, coaches and physical teachers should constantly ask the meaning of motions in performance and consciousness during performance.

4) Based on an observed performance, "virtual self-movement" is to virtually imagine this performance processes from a coaching standpoint.

5) Regarding the reason of categorizing three activities in "Sympathy of Movement", Kaneko (2005, p. 126) indicated that even if coaches get information using the observation of movement and "inquiring," it does not mean interpreting athlete's experience. This is because it is only objective material and does not lead to interpreting the athlete's experience. To interpret athlete's experience, "virtual self-movement" should be practiced, which focuses on the athlete's experience from the coach's internal standpoint.

6) During the observation of movement, experienced coaches can sympathize with an athlete's performance from a coaching standpoint and analyze performances, such as jumping, running, and throwing (Meinel, 1960/1981, p. 176). Using this sympathy, they can consider advice for each individual.

7) In this consciousness, the movement process is interpreted as overlaps of past, present, and future processes. This internal phenomenon is called "the consciousness of internal time" (Husserl, 1950/2001, p. 85). Thus, phases in an athlete's internal viewpoint are captured as the overlap structure, and they differ from the objective viewpoint.

8) Regarding an implicit assumption of all psychological discussions in classic period, Merleau-Ponty (1951/1997, pp. 171-172) highlighted that "psychological actions or psychological things are given something," and we cannot access subjectivity in another's mind. In contemporary psychology, phenomenon of sympathy is interpreted using the "theory of mind" or "simulation theory" (Goldman, 1989; Gordon, 1986). These theories also share the implicit assumption that others' mind is hidden (Gallagher and Zahavi, 2008, p. 183).

9) Regarding the phenomenon of sympathy, Merleau-Ponty $(1951 / 1997$, p. 172) indicated that "I see you combining bones and flesh. I cannot understand your thinking even if you are here. I have to imagine and interpret from a witnessed sequence of physical expressions such as facial expressions, gestures and words." Similarly, since coaches cannot directly understand an athlete's consciousness, it is impossible to interpret the phenomenon "sympathy of movement" using the schema of subjectivity and objectivi- 
ty in natural science.

10) This is because even if a person misunderstands substantiality in objectivity, there can be no doubt about an interpretation being a subjective belief in transcendental subjectivity (Husserl, 1973/2012, p. 54).

11) This concept is called "epoché" (Husserl, 1913/1979, p. 139). It is to suspend judgments against natural attitude (natürliche Einstellung) about world existence. Based on this concept, a cognitive phenomenon is interpreted from a pure consciousness using a transcendental attitude.

12) In this study, understanding and interpreting have different meanings. In a case of cognition in objectivity, since there is a true and false cognition of substantiality, the cognition is judged using understanding or misunderstanding. On the other hand, in a case of cognition in "transcendental subjectivity," since a true and false cognition does not exist and there is only subjective belief to interpret a subject, this cognition is regarded as an interpretation.

\section{Acknowledgement}

I am grateful to two anonymous reviewers whom made many corrections and suggestions which improved this paper immeasurably.

\section{References}

Gallagher, S. and Zahavi, D. (2008). The phenomenological mind: An introduction to philosophy of mind and cognitive science. London: Routledge.

Goldman, A. I. (1989). Interpretation psychologized. Mind Lang, 4: 161-185.

Gordon, R. M. (1986). Folk psychology as simulation. Mind Lang, 1: 158-171.

Finlay, L. (2009). Debating phenomenological research methods. Phenomenol. Pract., 3: 6-25.

Hamauzu, S. (1995). 「超越論的他者」とは何だったのか? [What is “Transcendental other”]. Ann. Rev. Phenomenol. Assoc. Jpn., 10: 149-163. (in Japanese)

Husserl, E. (1979). イデーン I-I 純粋現象学と現象学的哲学の ための諸構想 第 1 巻 純粋現象学への全般的序論 (J. Watanabe Trans.). Tokyo: Misuzu Shobo. (Original work "Ideen $\mathrm{zu}$ einer reinen phänomenologie und phänomenologischen philosophie. Erstes buch: Allgemeine einfuhrung in die reine phanomenologie [Ideas pertaining to a pure phenomenology and to a phenomenological philosophy-First book: General introduction to a pure phenomenology]' published 1913)

Husserl, E. (2001). イデーン II-I 純粋現象学と現象学的哲学の ための諸構想 第 2 巻 構成についての現象学的諸研究 (H. Tatematsu \& Y. Bessho Trans.). Tokyo: Misuzu Shobo. (Original work "Ideen zu einer reinen phänomenologie und phänomenologischen philosophie [Ideas pertaining to a pure phenomenology and to a phenomenological philosophy-Second book: Studies in the phenomenology of constitution]" published 1952)

Husserl, E. (2001). デカルト的省察 (S. Hamauzu trans.). Tokyo: Iwanami Shoten. (Original work "Cartesianische meditationen und pariser vorträge [Cartesian meditation and paris talking]"' published 1950)

Husserl, E. (2012). 間主観性の現象学 その方法 (S. Hamauzu \& I. Yamaguchi Trans.). Tokyo: Chikuma Shobo. (Original work "Zur phänomenologie der intersubjektivität [Phenomenology of intersubjectivity]" published 1973)
Kaneko, A. (1987). Zur morphologie der bewegungsbeobachtung im sport [Morphology of movement observation in sport]. Bull. Inst. Health Sport Sci., Univ. Tsukuba, 10: 113-124.

Kaneko, A. (2002). わざの伝承 [Hand down technique]. Tokyo: Meiwa Publishing. (in Japanese)

Kaneko, A (2005). 身体知の形成下 運動分析論講義·方法編 [Making body intelligence Volume 2. Lecture of analyzing performance-Methodology]. Meiwa Publishing Co. (in Japanese)

Killing, W. (1993). NSA Photosequences 24 \& 25-High Jump: Heike Henkel \& Inga Babakova. N. Stud. in Athletics, 8: 61-75. England: Marshallarts Print Services Co., Ltd.

Martínkovä, I. and Parry, J. (2011). An introduction to the phenomenological study of sport. Sport Ethics Philos., 5: 185-201.

Meinel, K. (1981). マイネル・スポーツ運動学 (A. Kaneko Trans.). Tokyo: Taishukan publishing. (Original work "Bewegungslehre: Versuch Einer Theorie der sportlichen Bewegung unter pädagogischem Aspekt [An experiment of sport movement theory under an educational aspect]" published 1960)

Merleau-Ponty, M. (1997). Les relations avec autrui chez I'enfant [Infant's Interpersonal relationship]. Parcours 1935-1951. Lagrasse: Verdier.

Muraki, Y. (1993). The whole and part of movement during coaching; Focusing on jumpers. Sci. Phys. Educ., 43: 973-980. (in Japanese)

Smith, D. W. (1989). The circle of acquaintance. Perception, consciousness, and empathy. Dordrecht: Kluwer Academic Publishers.

Schmolinsky, G. (1978). Track and field. Berlin: Sportverlag.

Tidow, G. (1993). Model technique analysis sheets part VIII: The flop high jump. N. Stud. Athletics, 8: 31-44.

Wertz, F. J. (2005). Phenomenological research methods for counseling psychology. J. Couns. Psychol., 52: 167-177.

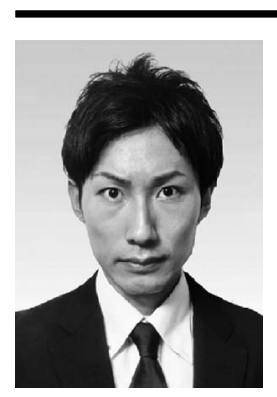

Name:

Naoki Matsuyama

Affiliation:
Graduate School of Sport Sciences,
Waseda University
Address:
2-579-15 Mikajima, Tokorozawa, Saita-
ma 359-1192 Japan Brief

\section{Biographical History:}

Naoki Matsuyama, a Ph.D. student at Waseda Graduate School of Sport Science, focuses in his major study on the exploration of athletes' consciousness by using philosophy of Husserl's phenomenology. Because he himself practices high jump since junior high school, his interests focus especially on elite high jumpers.

-2016 Visiting Research Student of Loughborough University -2014-2017 Doctor's program in Waseda Graduate School of Sport Science

-2011-2013 Master's program in Graduate School of Tokyo Gakugei University

\section{Main Works:}

-Analysis of Perceptual Phenomenon on Movement Observation: Interpretation of Morphological Viewpoint as "Dop- 
pelter Gestaltkreis" Sport Mont “Journal of Sport: physical education and health". 43-45/XIII. pp. 17-21

Membership in Learned Societies:

-International Association for the Philosophy of Sport

-Japan Society for the Philosophy of Sport and Physical Education 